\title{
The Impact of COVID-19 on the Delivery of an Evidence-Based Child Maltreatment Prevention Program: Understanding the Perspectives of SafeCare ${ }^{\circledast}$ Providers
}

\author{
Shannon Self-Brown ${ }^{1} \cdot$ Katherine Reuben ${ }^{1} \cdot$ Elizabeth W. Perry ${ }^{1} \cdot$ Lindsey R. Bullinger $^{2} \cdot$ Melissa C. Osborne $^{3}$. \\ JoAnne Bielecki ${ }^{1} \cdot$ Daniel Whitaker ${ }^{1}$
}

Accepted: 1 November 2020 / Published online: 5 November 2020

(C) Springer Science+Business Media, LLC, part of Springer Nature 2020

\begin{abstract}
Child maltreatment $(\mathrm{CM})$ is a global public health problem. Evidence-based home visiting programs, such as SafeCare ${ }^{\circ}$, reduce $\mathrm{CM}$ risk, and enhance parent-child relationships and other protective factors. As the result of the COVID-19 pandemic and resulting restrictions, SafeCare Providers transitioned from home to virtual delivery for the SafeCare curriculum. The purpose of this study is to 1) examine active SafeCare Providers' opinions on the feasibility and effectiveness of SafeCare via remote delivery, and 2) better understand workforce concerns for human service professionals within the context of COVID-19 mitigation efforts. Data are from a cross-sectional survey of SafeCare Providers $(N=303)$ in the United States, Canada, and Australia. The majority of Providers reported they were actively delivering SafeCare virtually and were comfortable with the delivery format. Providers indicated that the majority of SafeCare families are making progress on target skills, and that engagement is high among many families. Some service delivery challenges were reported, ranging from family data plan limitations to difficulty with delivery of specific components of the SafeCare curriculum related to modeling and assessment. The impact of COVID-19 on Providers' daily routines, stress level, and work-life balance has been significant. Remote, virtual delivery of CM prevention programming offers the opportunity to continue serving vulnerable families in the midst of a pandemic. Barriers related to family technology and data access must be addressed to ensure reach and the effective delivery of prevention programming during the pandemic and beyond.
\end{abstract}

Keywords Child maltreatment $\cdot$ SafeCare $\cdot$ Evidence-based programs $\cdot$ Parenting $\cdot$ Virtual delivery $\cdot$ COVID-19

Child maltreatment (CM) is a significant global public health problem (Hammond et al. 2006; Tarantola 2018) that increases the risk for long-term impacts on mental and physical health (Brown et al. 2010; Corso et al. 2008; Dong et al. 2003; Dong et al. 2004; Dube et al. 2009). Little research has examined how disaster and community wide trauma in industrialized or developed nations impact child maltreatment risk. The few published studies to date following natural disaster events in the United States suggest a significant link, with documented increases in abusive head trauma and child abuse

JoAnne Bielecki

jbielecki@gsu.edu

Daniel Whitaker

dwhitaker@gsu.edu

1 School of Public Health, Georgia State University, P.O. Box 3995, Atlanta, GA 30302, USA

2 School of Public Policy, Georgia Institute of Technology, 685 Cherry Street, Atlanta, GA 30332, USA

3 Byrdine F. Lewis College of Nursing and Health Professions, Georgia State University, P.O. Box 4019, Atlanta, GA 30302-4019, USA 
reports in the aftermath (Curtis et al. 2000; Keenan et al. 2004; Self-Brown et al. 2013). Further, studies have examined the impact of the 2008 Great Recession and war time on CM perpetration risk and found increases in harsh parenting and spanking (Brooks-Gunn et al. 2013) and lower levels of parental warmth (Eltanamly et al. 2019).

With the World Health Organization's declaration of COVID-19 as a global pandemic (Perc et al. 2020), there is much to learn about how the resulting circumstances will impact CM risk. Unlike the community togetherness that often emerges in times of community-wide disaster circumstances, the response to COVID-19 across the world has been to mandate physical separation with shelter in place and stay at home orders (Campbell 2020). Resulting consequences have included unemployment, reduced income, limited resources, alcohol abuse, intimate partner violence, and limited social support, which are all factors found in prior research to increase $\mathrm{CM}$ risk (Bright et al. 2018; Catalá-Miñana et al. 2017; Lindo et al. 2018; Lowell and Renk 2017; Paxson and Waldfogel 2002; Schenck-Fontaine et al. 2017). Additionally, many parents are now expected to work from home, which can increase the risk for inadequate child supervision and unintentional child injury (e.g., while parents are working; Feely et al. 2020). Due to COVID-19 concerns, parents may also be delaying child medical care, which could result in medical neglect for emerging health issues (Santoli et al. 2020; Wenner Moyer 2020).

With the increased parenting burden many families are experiencing, news reports have indicated that there are increases in calls to parenting helplines. For instance, National Parent Helpline calls in the United States increased 30\% in early April, with calls focused on concerns about child care, food, and other virusrelated stressors (Hurt et al. 2020). Anecdotal evidence from the United States, China, Brazil, and Australia indicate increases in violence to children due to isolation and quarantine (Campbell 2020; Peterman et al. 2020; van Gelder et al. 2020), and preliminary data from hospitals supports increases in severe child abuse and neglect (CBS Dallas Fort Worth 2020). However, child protection service settings have consistently documented significant drops in reports of CM, especially in countries with similar mandated reporting laws like the United States, Canada, and Australia (Matthews and Kenny 2008). For instance, a recent working paper by Baron et al. (2020) calculated the number of child maltreatment allegations in Florida and found that in March and April 2020, these were 27\% lower (212,500 cases) than would be expected (Baron et al. 2020). Further, Whaling et al. (2020) documented that the frequency of case openings in New York City in March 2020 was significantly lower than the frequency of case openings during the same month for the prior 7 years (March 2013-2019; Whaling et al. 2020). These declines do not likely reflect the true incidence rates, but instead are the result of lower child access to mandated reporters who are typically responsible for approximately $67.3 \%$ of child welfare allegations (U.S. Department of Health, and Human Services, Administration for Children and Families, Administration on Children Youth and Families and Children's Bureau 2020). Clearly, this is a very complicated time, and children may not be getting adequate protections. Given the current circumstances and associated risks, our society runs the risk of a substantial number of children at risk for child maltreatment being unidentified, overlooked, and underserved (Whaling et al. 2020).

\section{COVID-19 and Evidence-Based CM Prevention Programming}

Vulnerable, high-risk families may be engaged in CM prevention programming following involvement with child protective services or via other referral-based systems that connect families to programming through available community prevention efforts. In the United States, state child protection systems have begun to adopt evidence-based interventions, and recent federal child welfare legislation - the Families First Prevention and Services Act of 2017 - will accelerate the adoption of such programs. The California EvidenceBased Clearinghouse for Child Welfare (CEBC n.d.) rates three programs as "Supported" in the area of "Parent Training to Address Child Abuse and Neglect;" two of the three are delivered via home visiting. For broader prevention, the Home Visiting Evidence of Effectiveness (HomVEE; U.S. Department of Health and Human Services and Administration for Children and Families n.d.) identifies the quality of home visiting models, based on research evidence, used for broad prevention efforts with pregnant women and children from birth to kindergarten entry. Similar dissemination efforts are ongoing in Australia (Australian Research Alliance for Children and Youth 2020; Parenting Research Centre 2020) and Canada (Gallito et al. 2020; National Collaborating Centre for Determinants of Health 2009; Romano et al. 2020). The goals of these programs, whether delivered in child protection or prevention service settings, is to promote childhood health, safety, and development and improve parenting skills and responsible parenting among mothers and fathers, which correspond with decreases in maltreatment risk (Howard and Brooks-Gunn 2009; Supplee and Adirim 2012). An additional benefit of many of these programs is the resulting positive parent-child relationships, which are documented as a protective factor in helping children recover from large scale trauma events such as the terrorist attack in the U.S. on September 11, 2001, (Lutz et al. 
2007), war (Eltanamly et al. 2019), and natural disasters (e.g., Hurricane Katrina; Salloum and Lewis 2010), and could be a protective factor in the COVID-19 pandemic.

Collectively, evidence-based home visiting programs reach hundreds of thousands of vulnerable families a year in the United States alone (National Home Visiting Resource Center 2019). While these services are certainly needed during the COVID-19 pandemic to address the increased family risk, the continuation of home visiting services has been difficult due to concerns for worker and family safety (Crary 2020; Hardison 2020; Kelly and Hansel 2020). Home visits were suspended in many U.S. states and abroad, and consequently, numerous evidence-based home visiting programs have been exploring the use of virtual session delivery via telephone and/or video communication in lieu of face-toface home visits (Health Resources and Services Administration and Maternal and Child Health Bureau 2020; National Alliance of Home Visiting Models 2020).

In recent years, there has been growing evidence for the effectiveness and acceptability of telehealth and video-based counseling and therapy for children typically developed in clinic settings (Nelson and Sharp 2016). However, little is known about how well virtual services can work for parenting programs typically delivered via home visits and there are questions regarding both feasibility and effectiveness. A recent published report that summarizes a survey of evidence-based home visiting programs during the pandemic in the United States, conducted by the Home Visiting Applied Research Collaborative (HARC; O'Neill et al. 2020), suggest that multiple modalities are being used to replace in home visits, including interactive video conferencing, telephone, and texting. The most noted challenges regarding feasibility are that families (approximately 50\%) do not have stable internet access. This is not surprising given the literature noting issues with a digital divide and the social injustice that not all families have access to the internet and internet-enabled devices (Farakas and Romaniuk 2020; Goldschmidt 2020). Other noted issues for families documented by the survey included parent challenges with having the emotional capacity to engage in programs during the current circumstances and constraints related to confidentiality. For providers, challenges included reduced capacity to deliver curricula effectively given their own home environment issues (O'Neill et al. 2020).

The goal of this study is to present findings from a recent survey on the feasibility and effectiveness of virtual delivery of SafeCare ${ }^{\circledR}$ and to better understand workforce concerns. SafeCare is a home visiting program designed for parents of children aged $0-5$ years and targets proximal risk factors for physical abuse and neglect (Self-Brown et al. 2014). This program is typically delivered weekly in the home over 18 sessions by a trained SafeCare Provider, and includes three modules: Child Health, Home Safety, and Parent-Child Interaction. The Child Health module focuses on helping parents identify symptoms of illness and injury and take appropriate action. Training in this module includes parental psychoeducation pertaining to common childhood illness and injury and preventative health care, and parental practice of decision-making steps in response to hypothetical child health scenarios. The Home Safety module focuses on teaching parents to identify and secure home hazards that pose a danger to children, and to supervise children around unsafe environments. Parent training in this module focuses on education to help caregivers identify hazards in their home, and then the active removal of hazards to reduce the risk of child unintentional injuries. The Parent-Child Interaction module seeks to build a positive parent-child relationship. Parent training includes psychoeducation followed by Providers modeling positive parent-child interactions to the caregiver and then the observation of the caregiver practicing these skills as they engage in daily activities and play with their child. Families receive all three modules, which can be delivered in any order. Each SafeCare module is planned for six sessions, though the number of sessions can vary depending on progress.

Recent evaluations have shown SafeCare to influence important outcomes, such as parenting behaviors and parenting stress (Whitaker et al. 2020), child maltreatment recidivism (Chaffin et al. 2012), and out-of-home placements (BeachyQuick et al. 2018). SafeCare Providers serve more than 6000 families per year, providing parent training and intervention services that reduce and prevent the maltreatment of young children. When the COVID-19 pandemic struck, SafeCare Providers quickly adapted to technology-based delivery, and the purveyors of SafeCare developed best practice guidelines for virtual delivery to allow for the continuation of services in this very vulnerable time. However, the extent to which Providers were successfully able to deliver SafeCare components is not known. Additionally, workforce challenges of service delivery during this time are also largely unknown. Thus, this study has two research aims: 1) examine active SafeCare Providers' opinions on the feasibility and effectiveness of SafeCare via virtual delivery, and 2) better understand workforce concerns for human service professionals within the context of COVID-19 mitigation efforts. As an exploratory aim, we examined whether key outcomes for Aim 1 and 2 differed according to the SafeCare Provider country of residence or SafeCare Provider experience. Results from this study will inform us whether delivering the SafeCare curriculum to families via technology, rather than solely in-person, is a feasible option for SafeCare delivery during times where home visiting is restricted (or even if preferred by the client). The present study seeks to fill a gap in the literature and will offer a data-based call to action for examining child prevention outreach during pandemics and beyond. 


\section{Methods}

\section{Participants}

Participants for the current study were recruited by email between June 3rd and June 16th of 2020 from a list of active SafeCare Providers registered in the National SafeCare Training and Research Center's training portal. A total of 1039 email invitations were sent. Inclusion criteria were: 1) active SafeCare Providers, which included certified SafeCare home visitor Providers who are currently delivering SafeCare to families, and active SafeCare Coaches and Trainers who are currently supporting SafeCare Providers through certification or in the post-certification process, and may also be delivering SafeCare to families; 2) Provider had a working email address with the National SafeCare Training and Research Center Portal. We excluded SafeCare Providers who reside within the European Union from this study, as they were not eligible to participate due to General Data Protection Regulation compliance. In total, 390 individuals viewed the consent form; 303 participants completed all survey sections and compose the final analytical sample for this study. This includes 222 (73.5\%) who had attained SafeCare Provider Certification and $80(26.5 \%)$ who had completed additional training to become a Certified SafeCare Trainer or Coach.

Most SafeCare Providers resided in the United States ( $n=$ $286,94.4 \%)$, and the remainder $(n=17,5.6 \%)$ resided in another country (Australia, Canada). The majority provided services in an urban cluster/suburb ( $n=144,47.8 \%)$, while $27.2 \%(n=82)$ provided services in urban areas, and $24.9 \%$ $(n=75)$ provide services in rural areas. The experience level for participants was similar across categories, with $24.4 \%(n=$ 74) having less than 1 year of experience, $27.7 \%(n=84)$ reporting one to two years of experience, $22.8 \%(n=68)$ reporting two to four years of experience, and $25.1 \%(n=$ 75 ) having five or more years of experience. This study survey did not include questions related to age or gender. However, based on prior research with SafeCare providers, it is likely that $90 \%$ or more of the providers were female (Self-Brown et al. 2017; Whitaker et al. 2019), with an average age of midto late-30's.

\section{Procedure}

Active SafeCare Providers were emailed an invitation to participate in the survey, along with the survey link, to the address listed in the NSTRC portal. Those who clicked the link were taken to a Qualtrics survey that first presented a consent form, approved by the Institutional Review Boards at the two sponsoring institutions, which provided detailed information about the purpose of the survey and the opportunity to receive a \$15 Amazon gift card for survey completion. Providers who consented to the study were allowed to proceed to the main survey that included questions pertaining to how SafeCare delivery, the SafeCare workforce, and SafeCare families were being impacted by the COVID-19 pandemic.

The main survey was anonymous and collected no identifying information. Participants were given the option to request a gift card by following a link at the end of the survey, which collected participants' names and email addresses. Responses were not linked between the main and reimbursement surveys. Responses were included in the analysis if they were recorded in Qualtrics as 99-100\% complete $(n=303)$, indicating that the participant viewed all pages of the survey. This was done in order to minimize the likelihood that duplicate responses were included in the final analytical sample.

\section{Measures}

SafeCare COVID-19 Survey For purposes of the current study, three sections of the survey were examined. All survey items were developed by the authors. First, the demographic questions asked about participants' SafeCare experience and location of service delivery. The second section inquired about virtual delivery of SafeCare. Questions inquired about the technology capabilities of the families served, the strengths and challenges of remote SafeCare delivery, technical aspects of remote delivery such as keeping families engaged, and factors that would improve the experience of remote delivery for Providers. A third section included questions on how COVID-19 was impacting Providers, Trainers, and Coaches in their daily, financial, and emotional lives. Specifically, questions were asked about how the pandemic impacted the work of participants, how they were coping, and what could be done to support them during the pandemic. A selection of items from the survey is shown in Table 1.

\section{Data Analysis Plan}

Descriptive data from the survey were analyzed in IBM SPSS 25 (IBM Corp. 2017). Chi-square analyses were completed to examine if SafeCare provider country of residence (U.S., Canada, or Australia) and SafeCare provider experience (less than 1 year of SafeCare experience or greater than 1 year experience) was significantly associated with key variables for study Aim 1 and Aim 2. Aim 1 outcomes examined include: Provider comfort with SafeCare delivery; family smart device ownership; family data plan access; Providers' opinions of family engagement in virtual delivery and progress on SafeCare skills. Aim 2 outcomes of interest for the chi-square analyses were: impact of COVID-19 impact on the daily life; and impact of COVID-19 on work hours of SafeCare providers. Open ended responses from the survey were examined by four research team members to identify consistent response themes. Where relevant, 
frequencies of the number of times a theme was listed in open response items were computed using the frequency of the word(s) as numerator and the total number of open-ended responses as the denominator.

\section{Results}

\section{Aim 1: Examine Active SafeCare Providers' Opinions on the Feasibility and Effectiveness of SafeCare Via Virtual Delivery}

The majority of SafeCare Providers $(n=263,87.1 \%)$ indicated they thought that maltreatment risk had increased during the pandemic period, suggesting that finding effective options for continuing prevention programming are imperative. More than half of the participants reported that they had transitioned to conducting all SafeCare sessions remotely $(n=190$, $62.7 \%)$, while over a quarter of the sample $(n=92,30.4 \%)$ reported conducting both remote and in-person SafeCare sessions. In total, $87.1 \%$ of participants $(n=255)$ reported that they had completed a remote session, and $83.1 \%(n=24)$ indicated that they were comfortable with this virtual delivery (39.7\% somewhat comfortable, $43.4 \%$ very comfortable). Approximately $76 \%$ of Providers $(n=230)$ reported that they had enrolled a new family in virtual delivery of the SafeCare program. The most commonly used applications for virtual delivery were Zoom (50\%), FaceTime (19\%), and Google Duo $(15 \%)$. Providers overwhelmingly reported using their smartphones for session delivery $(n=202,66 \%)$. In terms of family technology access, participants indicated that the majority of the families they serve own a smart device $(n=258$, $87.8 \%$ ) and reported that the parents they served had the skills to use the smart device to engage effectively in a SafeCare session $(n=231,89.9 \%)$. Providers noted that approximately $21 \%$ of the families they serve do not have a sufficient data plan to allow them to use the device effectively for SafeCare sessions.

With regard to virtual delivery feedback specific to the SafeCare modules, the large majority of participants $85.8 \%$ $(n=212)$ reported that the Child Health module is similar or easier to deliver virtually than in home visitation. This module focuses largely on parental psychoeducation pertaining to common childhood illness and injury and preventative health care, with a practice component that consists of parents responding to written scenarios for how to best respond to illness and injury scenarios (i.e., treat at home, call the doctor, go to emergency room). Conversely, for the other two SafeCare modules (Home Safety, Parent-Child Interaction) that both include more active skill modeling and practice in the home environment, the majority of Providers indicated a greater difficulty in remote delivery $(n=215,87.4 \%$ for Home Safety; $n=188,77.4 \%$ for Parent-Child Interaction). Results were mixed regarding family engagement in virtual delivery, with $54.3 \%(n=139)$ of participants reporting that SafeCare session engagement for virtual delivery is either about the same (39\% respectively) or better than in-person sessions (15.3\% respectively); $45.3 \%(n=115)$ endorsed less engagement than during home visit delivery. SafeCare Provider participants noted a variety of tactics they are utilizing to increase virtual session engagement, including holding sessions at alternate times ( $n=230,75.7 \%$ ), using texts between sessions to maintain connection $(70.4 \%)$, dividing or chunking sessions into parts $(51.3 \%)$, and (19.6\%) providing tablets or smart devices to families in need. For this item, an "other" option was included, and some Providers also reported, through an open response option, dropping off care packages and scheduling "yard visits" to keep some connection with families in person.

Participants indicated that families were progressing positively on SafeCare target skills during virtual delivery, with approximately $60 \%$ noting that parent target skill improvement is about the same rate or occurs more quickly as compared to traditional home visit sessions. However, a considerable proportion $(n=98,40.3 \%)$ of Providers noted that family improvement was either a bit slower or much slower with remote delivery. When asked for open ended feedback on the successes of virtual delivery, participants shared numerous examples of positive family engagement and progress. For instance, one participant stated, "Parents are implementing parent-child interaction skills a lot more since children are home all day. Parents especially like to use these skills during play time and homework time." Several others included open ended comments indicating that "parents have been engaged," "retention seems higher," "parents like that sessions are less intrusive since Providers are not required to be in home," and "clients are completing the modules with success and mastery of target skills." In terms of challenges, open ended comments were largely focused on issues with technology and internet connection, difficulties with the provider modeling parenting and home safety skills for parents, and uncertainty about the accurate assessment of home hazards and hazard removal to promote child safety.

None of the chi-square analyses examining Aim 1 key outcomes with SafeCare Provider experience or country of residence were found to be significant. SafeCare experience was not associated with Provider comfort with remote delivery $\left(\chi^{2}[4, N=295],=8.88, p=.064\right)$; family engagement $\left(\chi^{2}\right.$ $[4, N=254],=3.60, p=.463)$; or family improvement $\left(\chi^{2}[4\right.$, $N=243],=7.95, p=.094)$. Similarly, a significant association did not emerge between Provider country of residence and Provider opinion of family engagement $\left(\chi^{2}[4, N=303]\right.$, = 4.33, $p=.363)$; family improvement $\left(\chi^{2}[4, N=303]\right.$, = $5.20, p=.268)$; likelihood of family smart device ownership $\left(\chi^{2}[1, N=303],=.004, p=.950\right)$; or family sufficient data plan $\left(\chi^{2}[2, N=303],=2.57, p=.277\right)$. 
Table 1 Sample items and response options from the SafeCare COVID-19 provider survey

\begin{tabular}{|c|c|c|}
\hline Number & Item & Response Options \\
\hline 52 & $\begin{array}{l}\text { In general, do most of your families own a smart device (computer with a } \\
\text { camera, smart phone, etc.)? }\end{array}$ & Yes or No \\
\hline 54 & $\begin{array}{l}\text { In general, do your families have a sufficient data plan to allow them to use } \\
\text { the device during SafeCare sessions? }\end{array}$ & Yes, No or Not sure \\
\hline 56 & $\begin{array}{l}\text { How would you rate your comfort with remote delivery technology } \\
\text { (computer with a camera, smart phone, tablet, etc.)? }\end{array}$ & $\begin{array}{l}\text { Rated using a Likert Scale }(1=\text { Extremely uncomfortable to } \\
5=\text { Extremely comfortable })\end{array}$ \\
\hline 62 & $\begin{array}{l}\text { Please select the response that most accurately describes the impact of } \\
\text { technology delivery on family engagement. }\end{array}$ & $\begin{array}{l}\text { Rated using a Likert Scale }(1=\text { Much less family engagement to } \\
5=\text { Much more family engagement })\end{array}$ \\
\hline 65 & $\begin{array}{l}\text { When sessions are delivered remotely, are families improving at the same } \\
\text { rates as they typically do for in-person sessions? }\end{array}$ & $\begin{array}{l}\text { Rated using a Likert Scale }(1=\text { Much slower remotely to } \\
5=\text { Much quicker remotely) }\end{array}$ \\
\hline 92 & As a result of the COVID-19 outbreak, have your work hours changed? & $\begin{array}{l}\text { Ranging from Fewer hours, No change, Same number of hours } \\
\text { but different schedule, Longer hours }\end{array}$ \\
\hline 96 & Overall, how much is COVID-19 impacting your day-to-day life? & Rated using a Likert Scale $(1=$ Not at all to $5=$ Extremely $)$ \\
\hline
\end{tabular}

\section{Aim 2: Workforce Concerns for Human Service Professionals within the Context of COVID-19 Mitigation Efforts}

Overall, COVID-19 has had a significant impact on the daily life and habits of SafeCare Providers. The majority of participants $(n=255,85 \%)$ reported a moderate to extreme impact on their own day-to-day lives as a result of COVID-19. Providers reported that the most impacted daily habits included leaving home less often ( $n=253,83.2 \%)$, socializing less often ( $n=230,75.7 \%$ ), and leaving home only for essential needs $(n=208,68.4 \%)$. The majority of participants also reported increases in caretaking responsibilities for children or a sick loved one $(n=140,78.2 \%)$.

In terms of employment and financial impact, participants reported that slowed business for someone in their household ( $n=77,25.3 \%$ ) and paying bills for things they are not currently using ( $n=77,25.3 \%$ ), such as daycare, had the biggest impact on their financial security. Notably, no Providers from outside the US (Canadian and Australian respondents) reported slowed business or paying bills for non-utilized services as a concern. The majority of participants $(n=226,75.3 \%)$ reported that they did not experience a change in work hours, or they worked the same number of hours but on a different schedule. Only $15.3 \%$ of Providers reported working longer hours.

When asked about the biggest ways in which the outbreak has impacted their work, many Providers noted the impact of delivering sessions virtually from their home environment as a challenge in terms of maintaining confidentiality of clients being served and home-life balance. For instance, in response to the question "In what ways does COVID-19 impact your personal ability to fulfill your role as a provider?", one participant noted, "Sessions were conducted in my home and it could be difficult to find a space that would keep confidentiality in place. Family members would sometimes walk into the room [where] I was conducting sessions without realizing I was on a call. They did not see the client, but it was a distraction for me as a provider to have to tell them to leave and then ensure to the family that their privacy was not breached." Another participant stated, "...having to balance taking care of my son and work. I have to have my son do more things independently while I am doing sessions." Similarly, another participant indicated, "Balancing work and personal life is a major deal for many of us Providers." Several Providers also noted that they really miss having the personal connection with families that in-person sessions allow. Another common response highlighted by several participants acknowledged the challenge of being there for others in a time when everyone is experiencing so much anxiety and uncertainty. For instance, one Provider stated, "My personal anxiety level has been high. At times it has been difficult to be positive and helpful when families are struggling." Similarly, another Provider indicated, "It has been difficult mentally for me to lose contact with friends and family and practicing selfcare, while attempting to continue to help consumers at work."

Nearly three-quarters of participants $(n=218,72.0 \%)$ reported that they are moderately to extremely concerned about becoming infected with COVID-19. A smaller majority indicated they were moderately to extremely concerned about contracting COVID-19 through work ( $n=215,67.9 \%)$. In open ended responses to the question "How is the outbreak affecting your quality of life and mental state?", approximately $40.2 \%$ of participants noted feeling overwhelmed or experiencing anxiety, stress, depression, or worry during this time. In terms of self-care, participants described going for walks ( $n=219,72.0 \%)$, connecting with loved ones using technology $(n=213,70.1 \%)$, making meals $(n=197$, $64.8 \%)$, having more in-person family time $(n=150$, 
$49.3 \%)$, doing creative activities $(n=127,41.8 \%)$, and spending time on a hobby $(n=126,41.4 \%)$.

Two chi-square analyses emerged as significant for outcomes related to the impact of COVID-19 on the workforce based on country of residence. Notably, Providers in the United States were more likely than Providers from other nations to be very or extremely concerned about contracting COVID-19 ( $\left.\chi^{2}[4, N=303],=15.75, p=.003\right) .40 .2 \%$ of US Providers $(n=115)$ were very or extremely concerned compared to only one Provider outside of the US (5.9\%). Slowed business was especially a problem for Providers in the United States $\left(\chi^{2}[1, N=303],=4.58, p=.032\right)$, affecting $26.9 \%$ of US Providers ( $n=77$ ); no Providers from outside the US reported this as a concern. SafeCare Provider experience was associated with work hour changes $\left(\chi^{2}[3, N=300]\right.$, = 21.09, $p=.012$ ); Providers who had worked for less than 1 year were more likely to have their hours reduced $(12.3 \%$ compared to $8.4 \%$ ) and more likely to have their schedule changed (43.8\% compared to $31.3 \%$ ) than all other Providers.

\section{Discussion}

COVID-19 has increased risk factors associated with CM perpetration worldwide, such as unemployment, reduced income, alcohol abuse, intimate partner violence, and limited social support (Bright et al. 2018; Catalá-Miñana et al. 2017; Lindo et al. 2018; Lowell and Renk 2017; Paxson and Waldfogel 2002; Schenck-Fontaine et al. 2017). While there have been some reports that calls to parent helplines have increased during the pandemic (Hurt et al. 2020), child maltreatment allegations are lower than would be expected for countries with similar mandated reporting laws, like the U.S., Canada, and Australia, likely due to limited child access to mandated reporters (Baron et al. 2020). Evidence-based programs that serve families involved with child protection and prevention service settings have an increasingly broad reach and have been found to reduce risk for $\mathrm{CM}$ perpetration and recidivism (Chaffin et al. 2012; Howard and Brooks-Gunn 2009; Supplee and Adirim 2012). Due to COVID-19, many of these programs, which are delivered in the home setting were suspended in the U.S. and abroad, resulting in a quick shift to virtual session delivery. This exploratory study examined the feasibility and effectiveness of virtual delivery for one evidence-based program, SafeCare, by surveying active SafeCare professionals working in the U.S., Australia, and Canada. Additionally, the study examined current workforce concerns and challenges among SafeCare Providers in the midst of the pandemic.

Notably, a majority of participants indicated they thought that maltreatment risk would increase during the COVID-19 pandemic period. The data are also convincing that providers remained committed to the continued delivery of child maltreatment prevention services during this time, with a substantial number of SafeCare Providers reporting active delivery of virtual sessions. Reported rates of SafeCare virtual delivery were commensurate with what was reported in the larger field of evidence-based home visiting in the recent HARC survey report (O'Neill et al. 2020). Importantly, most families served by SafeCare Providers do own a smart device and can effectively use them for session participation; however, data plan limitations and internet access for SafeCare families has negatively impacted active and ongoing participation. Recent PEW data indicate that approximately $71 \%$ of low-income individuals (the majority of SafeCare families live in low socioeconomic households; Whitaker et al. 2020) own a smartphone, but a much smaller percentage (59\%) have home broadband access (Pew Research Center 2018, 2019). In contrast, $94 \%$ of Canadians have home internet access (Theckedath 2020), and Australia is actively implementing internet plans for low-income households with school aged children as the result of the pandemic (Kidman 2020). It is imperative that we invest in efforts to remove these logistical barriers for all families to ensure equity and avoid exacerbating negative outcomes amongst the most at risk children and families. Global strategies to ensure affordable access to technology and broadband are necessary to prevent increases in access gaps for evidence-based programming, healthcare, and education.

There were some discrepancies between SafeCare Provider opinions and responses regarding the feasibility of virtual delivery according to SafeCare modules. Provider responses indicated that the SafeCare module that is the most didactic, Child Health, was the easiest to deliver virtually, while the two modules with more modeling and active role play, Home Safety and Parent-Child Interaction, were more challenging. There is a paucity of literature focused on how well telehealth or virtual delivery lends itself to more active teaching practices, such as modeling, role-play, and behavioral practice, that are critical aspects of evidence-based behavioral parenting interventions (Serketich and Dumas 1996) and a key aspect of improving target behavioral skills related to child maltreatment prevention. As the need for virtual delivery of programming continues, it will be key for purveyors of programs and service providers to become more systematic in their delivery of virtual programs. Purveyors may need to create materials (e.g., video clips) that allow families to view skills that are typically modeled, and create interfaces for families to submit rehearsal examples for review. Ironically, this may improve practice beyond in-person delivery as more consistency may emerge in how skills are modeled and reviewed.

In terms of family engagement and program effectiveness, SafeCare Providers' responses were mostly positive, suggesting that families are actively engaged and making positive progress in target skills. Providers reported several 
considerations and augmentations they were implementing to ensure positive engagement, with flexibility of session delivery time (evening and weekend delivery) and chunking of one session into multiple shorter sessions being two very commonly implemented strategies. While parent target skill mastery is reportedly taking longer to achieve via virtual delivery, Providers reported that parents are continuing to achieve skill mastery and success with this delivery format. Interestingly, some Providers commented on the increased opportunity that parents have to practice and implement the SafeCare skills they learn in session during the pandemic, and that the increased time with children appears to positively impact parent motivation to use the skills they are learning. Additionally, some Providers noted that the virtual delivery is perceived as less intrusive by parent program participants, given they can get the benefit of the service without allowing a provider into their home. Virtual delivery challenges were also noted, with the unreliability of technology being the most commonly reported. Other challenges include Providers struggling with target skill modeling and conducting accurate assessments, given the lack of best practice guidelines for how to navigate these skills over technology.

With regard to impact on the workforce, it is clear that SafeCare Providers' daily lives and habits are deeply impacted by the pandemic, especially in terms of home restrictions, decreased socializing, and increased caretaking responsibilities. Work responsibilities and finances were reportedly significantly impacted for approximately a quarter of the provider participants. Of note, based on the survey responses, U.S. SafeCare Providers' employment, especially related to decreased work hours, were significantly more impacted than Canadian and Australian Providers. Emerging literature suggests that rates/projection of unemployment are fairly consistent across the U.S., Canada, and Australia (approximately 10 to 15\%; Lemieux et al. 2020); however, perhaps human services positions are being differentially impacted. This would not be surprising based on the substantial differences that exist for policy and funding for human services across these countries. As would be expected, Providers who were newest to the job were also the most likely to experience reduced or changed hours.

SafeCare Providers are concerned about being infected with COVID-19 through work, with Providers living in the U.S. reporting significantly more concern than their Canadian and Australian counterparts. Despite these fears, SafeCare Providers are clearly engaged in their work and committed to continuing serving their caseloads however possible. This commitment has not been without negative consequences, as the Providers reported challenges with work-life balance and with managing their own feelings of anxiety, worry, and depression. Importantly, SafeCare Providers reported engaging in numerous positive self-care behaviors. Prior research has demonstrated that personal self-care activities play a critical role in reducing burnout and secondary trauma among human service professionals (Salloum et al. 2019). Thus, it is critical that supervisors and administrators supporting those working in human services, especially in the midst of this pandemic, are encouraging quality self-care to buffer negative outcomes for these critical professionals.

\section{Study Strengths and Limitations}

This study is the first to examine the impact of the COVID-19 pandemic on the delivery of an evidence-based child maltreatment home visiting program that has transitioned to virtual delivery, as well as the impact of COVID-19 on the workforce responsible for delivering these programs. However, there were some limitations to the study. The data were collected with a convenience sample, and approximately $29 \%$ of those invited completed the survey. Thus, there may be some bias or unanticipated motivations for the percent of Providers who completed the survey. For instance, perhaps those that responded were more greatly impacted by the pandemic and resulting circumstances, which made them more willing to participate. Or perhaps the converse is true, with those individuals not as impacted by COVID-19 having more time and energy to participate in such a survey. Unfortunately, this study did not allow for the comparison of Provider respondents to non-respondents on any variables that could allow us to determine if there are existing significant differences between groups.

The survey was self-reported, and all biases related to this form of data collection are relevant. Data collection occurred in June 2020 and may not accurately represent the impact of the pandemic during the most extreme restriction periods, or how the impact of the continued rise of cases in the U.S. occurring in July 2020 and beyond might impact ongoing virtual delivery and the workforce. Finally, no family-level data collection occurred, so the reports on family engagement and intervention progress are the subjective impressions of Providers and does not offer descriptors of families that were perhaps the most negatively impacted by COVID-19 with regard to the outcomes explored.

\section{Future Directions in Virtual Delivery of CM Prevention Programming}

Given the risks impacting our world's most vulnerable families during the COVID-19 pandemic, it is imperative to ensure effective and sustainable delivery of evidence-based programs that can reduce maltreatment risk for young children. Much more research is needed to ensure that virtual program delivery will lead to similar positive outcomes as in-person delivery, as well as an explication of the benefits and challenges associated with this delivery approach. Additional evidence supporting the successful virtual delivery of evidence-based 
CM prevention programming could lead to important benefits for the field as a whole, especially with regard to costs and time burden associated with home visiting program delivery. Much more research is needed with the parent consumers of these programs, to assess their feedback and preferences. If some parents prefer this mode of delivery given the higher flexibility and lower intrusiveness, as was suggested by SafeCare Providers who completed the current survey, then our field must respond in moving forward with identifying best practices and addressing challenges involved with virtual delivery.

For purveyors of evidence-based CM prevention programming, the results of this survey offer some information on how to best support program providers in transitioning to virtual delivery. First, we must reconsider our messaging about program fidelity. Many evidence-based programs have strict requirements for both the program curriculum and process of delivery. If we engage in a shift of the delivery process, then we must ensure that the curriculum is flexible enough to shift across delivery modes and maintain the active ingredients that lead to positive outcomes for parents and families. Second, purveyors should consider what supports are needed to ensure effective virtual delivery. Offering webinars, connecting providers delivering programming in similar settings (e.g., settings where broadband issues may be greater), and treating best practice guidelines as a fluid document to be revised as lessons are learned, are just a few of the many suggestions the current survey feedback offered. Third, it is important to consider which curriculum adaptations are needed to advance virtual delivery, especially for assessments and programmatic materials that need to be shared with clients. Further, understanding if these program curricula should be augmented with information on COVID-19 is a consideration. Fourth, efforts encouraging and supporting positive provider self-care to address their own anxiety, household changes, and employment requirements are sorely needed. Given the personal impact of the current pandemic on trained SafeCare Providers, and although this study did not address parent-level outcomes, it may be worth noting that purveyors may want to consider the impact of incorporating parent self-care into curriculum adaptations on child maltreatment outcomes. Lastly, purveyors must consider what their recommended options for program delivery will be once home visits become safer. Will the programs remain flexible and consider hybrid approaches to delivery, or return to the status quo?

In conclusion, perhaps the two largest issues the CM prevention field must consider with virtual delivery is family access and child safety. Issues related to data plans and internet availability, or lack thereof, could increase disparities and reduce program reach for families who do not have the consistent access and, consequently, capacity for participating in virtual delivery. Also, we must better understand how well providers can accurately assess child safety and maltreatment risk virtually. That is, what are program providers able to effectively observe and assess in terms of child safety through technology, and how does this impact mandated reporting. These questions, and the further study of them within the context of randomized, prospective research designs, are imperative to the effective establishment of the next phase of child maltreatment prevention program delivery during the pandemic and beyond.

Funding This work was supported by the Georgia Tech Office of the Executive Vice President for Research COVID-19 Rapid Response Seed Grant Program. The content is solely the responsibility of the authors and does not necessarily represent the official views of Georgia Institute of Technology.

\section{Compliance with Ethical Standards}

Declarations of Interest The authors declare that they have no conflict of interest.

Informed Consent Informed consent was obtained from all individual participants included in the study.

\section{References}

Australian Research Alliance for Children and Youth. (2020). right@home.ARACY. Retrieved from https://www.aracy.org.au/ the-nest-in-action/righthome

Baron, E. J., Goldstein, E. G., \& Wallace, C. (2020). Suffering in silence: How COVID-19 school closures inhibit the reporting of child maltreatment. SSRN Electronic Journal. https://oi.org/10.2139/ssrn. 3601399.

Beachy-Quick, K., Lee, C., McConnell, L., Orsi, R., Timpe, Z., \& Winokur, M. (2018). SafeCare Colorado program evaluation report 2014-2017. Retrieved from http://35pytx37zdp5j4hfr35of829wpengine.netdna-ssl.com/ssw/wp-content/uploads/sites/7/2019/10/ SafeCare-Colorado-Project-Evaluation-Report-2014-2017_final_ corrected.pdf

Bright, M. A., Huq, M. S., Spencer, T., Applebaum, J. W., \& Hardt, N. (2018). Animal cruelty as an indicator of family trauma: Using adverse childhood experiences to look beyond child abuse and domestic violence. Child Abuse and Neglect, 76, 287-296. https://doi.org/ 10.1016/j.chiabu.2017.11.011.

Brooks-Gunn, J., Schneider, W., \& Waldfogel, J. (2013). The great recession and the risk for child maltreatment. Child Abuse \& Neglect, 37(10), 1-17. https://doi.org/10.1016/j.chiabu.2013.08.004.

Brown, D. W., Anda, R. F., Felitti, V. J., Edwards, V. J., Malarcher, A. M., Croft, J. B., \& Giles, W. H. (2010). Adverse childhood experiences are associated with the risk of lung cancer: A prospective cohort study. BMC Public Health, 10(20), 1-12. https://doi.org/10. 1186/1471-2458-10-20.

Campbell, A. M. (2020). An increasing risk of family violence during the Covid-19 pandemic: Strengthening community collaborations to save lives. Forensic Science International: Reports, 2(April), 100089. https://doi.org/10.1016/j.fsir.2020.100089.

Catalá-Miñana, A., Lila, M., Oliver, A., Vivo, J. M., Galiana, L., \& Gracia, E. (2017). Contextual factors related to alcohol abuse among intimate partner violence offenders. Substance Use and Misuse, 52(3), 294-302. https://doi.org/10.1080/10826084.2016.1225097. 
CBS Dallas Fort Worth. (2020, March 20). North Texas hospital reports spike in severe child abuse cases; believe linked to stress from Coronavirus pandemic. CBS Dallas Fort Worth. Retrieved from https://dfw.cbslocal.com/2020/03/20/texas-hospital-spike-severechild-abuse-cases-coronavirus/

CEBC. (n.d.). The California evidencce-based clearinghouse for child welfare professionals. Retrieved July 13, 2020, from https://www. cebc4cw.org/

Chaffin, M., Hecht, D., Bard, D., Silovsky, J. F., \& Beasley, W. H. (2012). A statewide trial of the SafeCare home-based services model with parents in child protective services. Pediatrics, 129(3), 509515. https://doi.org/10.1542/peds.2011-1840.

Corso, P. S., Edwards, V. J., Fang, X., \& Mercy, J. A. (2008). Healthrelated quality of life among adults who experienced maltreatment during childhood. American Journal of Public Health, 98(6), 1094 1100. https://doi.org/10.2105/AJPH.2007.119826.

Crary, D. (2020, March 28). Child welfare systems struggle during coronavirus pandemic. Chicago Sun Times. Retrieved from https:// chicago.suntimes.com/coronavirus/2020/3/28/21198168/childwelfare-coronavirus-pandemic

Curtis, T., Miller, B. C., \& Berry, E. H. (2000). Changes in reports and incidence of child abuse following natural disasters. Child Abuse and Neglect, 24(9), 1151-1162. https://doi.org/10.1016/S01452134(00)00176-9.

Dong, M., Dube, S. R., Felitti, V. J., Giles, W. H., \& Anda, R. F. (2003). Adverse childhood experiences and self-reported liver disease. Archives of Internal Medicine, 163(16), 1949-1956. https://doi. org/10.1001/archinte.163.16.1949.

Dong, M., Giles, W. H., Felitti, V. J., Dube, S. R., Williams, J. E., Chapman, D. P., \& Anda, R. F. (2004). Insights into causal pathways for ischemic heart disease. Circulation, 110, 1761-1766. https://doi.org/10.1161/01.CIR.0000143074.54995.7F.

Dube, S. R., Fairweather, D., Pearson, W. S., Felitti, V. J., Anda, R. F., \& Croft, J. B. (2009). Cumulative childhood stress and autoimmune diseases in adults. Psychosomatic Medicine, 71(2), 243-250. https:// doi.org/10.1097/PSY.0b013e3181907888.

Eltanamly, H., Leijten, P., Jak, S., \& Overbeek, G. (2019). Parenting in times of war: A meta-analysis and qualitative synthesis of war exposure, parenting, and child adjustment. Trauma Violence and Abuse, 1-4. https://doi.org/10.1177/1524838019833001.

Farakas, K. J., \& Romaniuk, J. R. (2020). Social work, ethics and vulnerable groups in the time of coronavirus and Covid-19. Society Register, 4(2), 67-82. https://doi.org/10.14746/sr.2020.4.2.05.

Feely, M., Raissian, K., Schneider, W., \& Bullinger, L. (2020). Practical steps to prevent child neglect in the COVID-19 pandemic. APSAC Alert, 11(3), 1-4 Retrieved from https://www.apsac.org/single-post/ 2020/04/22/New-APSAC-Alert-113-Practical-Steps-to-PreventChild-Neglect-in-the-COVID-19-Pandemic.

Gallito, E., Romano, E., \& Whitaker, D. J. (2020). Investigating the impact of the SafeCare program on parenting behaviours in child welfare-involved families. Child and Adolescent Social Work Journal. https://doi.org/10.1007/s10560-020-00672-6.

Goldschmidt, K. (2020). The COVID-19 pandemic: Technology use to support the wellbeing of children. Journal of Pediatric Nursing, 52, 88-90. https://doi.org/10.1016/j.pedn.2020.04.013.

Hammond, W. R., Whitaker, D. J., Lutzker, J. R., Mercy, J., \& Chin, P. M. (2006). Setting a violence prevention agenda at the centers for disease control and prevention. Aggression and Violent Behavior, 11, 112-119. https://doi.org/10.1016/j.avb.2005.07.003.

Hardison, E. (2020, March 26). 'The perfect storm:' How COVID-19 has multiplied the risk for children in abusive households. Pennsylvania capital star. Retrieved from https://www.penncapital-star.com/ covid-19/the-perfect-storm-how-covid-19-has-multiplied-the-riskfor-children-in-abusive-households/

Health Resources \& Services Administration, \& Maternal and Child Health Bureau. (2020). Important home visiting information during
COVID-19. Retrieved June 30, 2020, from https://mchb.hrsa.gov/ Home-Visiting-Information-During-COVID-19

Howard, K. S., \& Brooks-Gunn, J. (2009). The role of home-visiting programs in preventing child abuse and neglect. Future of Children, 19(2), 119-146. https://doi.org/10.1353/foc.0.0032.

Hurt, S., Ball, A., \& Wedell, K. (2020, April 16). Children more at risk for abuse and neglect amid coronavirus pandemic, experts say. USA Today. Retrieved from https://www.usatoday.com/story/news/ investigations/2020/03/21/coronavirus-pandemic-could-becomechild-abuse-pandemic-experts-warn/2892923001/

IBM Corp. (2017). IBM SPSS statistics for windows, version 25.0. Armonk: IBM Corp.

Keenan, H. T., Marshall, S. W., Nocera, M. A., \& Runyan, D. K. (2004). Increased incidence of inflicted traumatic brain injury in children after a natural disaster. American Journal of Preventive Medicine, 26(3), 189-193. https://doi.org/10.1016/j.amepre.2003.10.023.

Kelly, J., \& Hansel, K. (2020, March 11). Coronavirus: What child welfare systems need to think about. The Imprint. Retrieved from https://imprintnews.org/child-welfare-2/coronavirus-what-childwelfare-systems-need-to-think-about/41220

Kidman, A. (2020, April 17). Do I qualify for NBN Co's $\$ 150$ million coronavirus broadband relief package? Finder. Retrieved from https://www.finder.com.au/nbn-coronavirus-relief-package

Lemieux, T., Milligan, K., Schirle, T., \& Skuterud, M. (2020). Initial impacts of the COVID-19 pandemic on the Canadian labour market. In Working Paper Series, Canadian Labour Economics Forum (CLEF) (No. 26). https://doi.org/10.1057/st.2011.9.

Lindo, J. M., Schaller, J., \& Hansen, B. (2018). Caution! Men not at work: Gender-specific labor market conditions and child maltreatment. Journal of Public Economics, 163, 77-98. https://doi.org/10. 1016/j.jpubeco.2018.04.007.

Lowell, A., \& Renk, K. (2017). Predictors of child maltreatment potential in a national sample of mothers of young children. Journal of Aggression, Maltreatment and Trauma, 26(4), 335-353. https:// doi.org/10.1080/10926771.2017.1299825.

Lutz, W., Hock, E., \& Kang, M. J. (2007). Children's communication about distressing events: The role of emotional openness and psychological attributes of family members. American Journal of Orthopsychiatry, 77(1), 86-94. https://doi.org/10.1037/002-9432. 77.86.

Matthews, B., \& Kenny, M. C. (2008). Mandatory reporting legislation in the United States, Canada, and Australia: A cross-jurisdictional review of key features, differences, and issues. Child Maltreatment, 13(1), 50-63. https://doi.org/10.1177/1077559507310613.

National Alliance of Home Visiting Models. (2020). Rapid response virtual home visiting. Retrieved June 30, 2020, from https://www. nationalalliancehvmodels.org/rapid-response

National Collaborating Centre for Determinants of Health. (2009). PanCanadian inventory of public health early child home visiting: Key facts and glossary. Antigonish: NS: Author.

National Home Visiting Resource Center. (2019). 2019 home visiting yearbook: An overview. Retrieved from https://nhvrc.org/ yearbook/2019-yearbook/

Nelson, E. L., \& Sharp, S. (2016). A review of pediatric telemental health. Pediatric Clinics of North America, 63, 913-931. https://doi.org/10. 1016/j.pcl.2016.06.011.

O’Neill, K., Korfmacher, J., Zagaja, C., \& Duggan, A. (2020). COVID19's early impact on home visiting: First report from a national HARC-beat survey of local home visiting programs.

Parenting Research Centre. (2020, June 23). Reducing child abuse and neglect in NSW. Retrieved from https://www.parentingrc.org.au/ how-we-support-change/reducing-child-abuse-and-neglect-in-nsw/

Paxson, C., \& Waldfogel, J. (2002). Work, welfare and child maltreatment. Journal of Labor Economics, 20(3), 435-474. https://doi.org/ $10.1086 / 339609$. 
Perc, M., Gorišek Miksić, N., Slavinec, M., \& Stožer, A. (2020). Forecasting COVID-19. Frontiers in Physics, 8(127). https://doi. org/10.3389/fphy.2020.00127.

Peterman, A., Potts, A., O'Donnell, M., Thompson, K., Shah, N., OerteltPrigione, S., \& van Gelder, N. (2020). Pandemics and violence against women and children (working paper 528). Retrieved from Center for Global Development website: https://www.cgdev.org/ publication/pandemics-and-violence-against-women-and-children.

Pew Research Center. (2018). Demographics of mobile device ownership and adoption in the United States. Retrieved July 10, 2020, from https://www.pewresearch.org/internet/fact-sheet/mobile/

Pew Research Center. (2019). Demographics of internet and home broadband usage in the United States. Retrieved July 10, 2020, from https://www.pewresearch.org/internet/fact-sheet/internetbroadband/

Romano, E., Gallito, E., Firth, K., \& Whitaker, D. J. (2020). Does the SafeCare parenting program impact caregiver mental health? Journal of Child and Family Studies, 29, 2653-2665. https://doi. org/10.1007/s10826-020-01774-6.

Salloum, A., Choi, M. J., \& Stover, C. S. (2019). Exploratory study on the role of trauma-informed self-care on child welfare workers' mental health. Children and Youth Services Review, 101, 299-306. https:// doi.org/10.1016/j.childyouth.2019.04.013.

Salloum, A., \& Lewis, M. L. (2010). An exploratory study of african american parent-child coping strategies post-hurricane Katrina. Traumatology, 16(1), 31-41. https://doi.org/10.1177/ 1534765609348240.

Santoli, J. M., Lindley, M. C., DeSilva, M. B., Kharbanda, E. O., Daley, M. F., Galloway, L., et al. (2020). Effects of the COVID-19 pandemic on routine pediatric vaccine ordering and administration United States, 2020. Morbidity and Mortality Weekly Report, 69(19), 591-593. https://doi.org/10.15585/mmwr.mm6919e2.

Schenck-Fontaine, A., Gassman-Pines, A., \& Ananat, E. (2017). Local job losses and child maltreatment: The importance of community context. Social Service Review, 91(2), 233-263. https://doi.org/10. 1086/692075.

Self-Brown, S., Anderson, P., Edwards, S., \& McGill, T. (2013). Child maltreatment and disaster prevention: Qualitative study of community agency perspectives. Western Journal of Emergency Medicine, 14(4), 402-408. https://doi.org/10.5811/westjem.2013.2.16206.

Self-Brown, S., McFry, E., Montesanti, A., Edwards-Gaura, A., Lutzker, J., Shanley, J., \& Whitaker, D. (2014). SafeCare: A prevention and intervention program for child neglect and physical abuse (2nd Editio; R. M. Reece, R. F. Hanson, \& J. Sargent, Eds.). Baltimore, MD: Johns Hopkins University Press.

Self-Brown, S., Osborne, M. C., Rostad, W., \& Feil, E. (2017). A technology-mediated approach to the implementation of an evidence-based child maltreatment prevention program. Child Maltreatment, 22(4), 344-353. https://doi.org/10.1177/ 1077559516678482 .
Serketich, W. J., \& Dumas, J. E. (1996). The effectiveness of behavioral parent training to modify antisocial behavior in children: A metaanalysis. Behavior Therapy, 27(2), 171-186. https://doi.org/10. 1016/S0005-7894(96)80013-X.

Supplee, L., \& Adirim, T. (2012). Evidence-based home visiting to enhance child health and child development and to support families. Children, Youth and Families News.

Tarantola, D. (2018). Child maltreatment: Daunting and universally prevalent. American Journal of Public Health, 108(9), 1119-1120. https://doi.org/10.2105/AJPH.2018.304637.

Theckedath, D. (2020, May 13). The state of broadband internet in Canada. HillNotes. Retreived from https://hillnotes.ca/2020/05/13/ the-state-of-broadband-internet-in-canada-2/

U.S. Department of Health \& Human Services, Administration for Children and Families, Administration on Children Youth and Families, \& Children's Bureau. (2020). Child maltreatment 2018. Retrieved from https://www.acf.hhs.gov/cb/research-datatechnology/statistics-research/child-maltreatment.

U.S. Department of Health and Human Services, \& Administration for Children and Families. (n.d.). Home visiting evidence of effectiveness. Retrieved July 13, 2020, from https://homvee.acf.hhs.gov/

van Gelder, N., Peterman, A., Potts, A., O'Donnell, M., Thompson, K., Shah, N., \& Oertelt-Prigione, S. (2020). COVID-19: Reducing the risk of infection might increase the risk of intimate partner violence. EClinicalMedicine, 21, 100348. https://doi.org/10.1016/j.eclinm. 2020.100348.

Wenner Moyer, M. (2020, March 26). Doctors expect a "huge spike" in pediatric injuries at home. The New York Times. Retrieved from https://www.nytimes.com/2020/03/26/parenting/kids-injuriescoronavirus.html

Whaling, K., Der Sarkissian, A., Larez, N. A., Sharkey, J. D., Allen, M. A., \& Nylund-gibson, K. (2020). Reduced child maltreatment prevention service case openings during COVID-19. Research Square, 1-13. https://doi.org/10.21203/rs.3.rs-30930/v1.

Whitaker, D. J., Lyons, M., Weeks, E. A., Hayat, M. J., Self-Brown, S., \& Zahidi, R. (2019). Does adoption of an evidence-based practice lead to job turnover? Results from a randomized trial. Journal of Community Psychology, 48(4), 1258-1272. https://doi.org/10. 1002/jcop.22305.

Whitaker, D. J., Self-Brown, S., Hayat, M. J., Osborne, M. C., Weeks, E. A., Reidy, D. E., \& Lyons, M. (2020). Effect of the SafeCare(C) intervention on parenting outcomes among parents in child welfare systems: A cluster randomized trial. Preventive Medicine, 138, 106167. https://doi.org/10.1016/j.ypmed.2020.106167.

Publisher's Note Springer Nature remains neutral with regard to jurisdictional claims in published maps and institutional affiliations. 